\title{
Parasitofauna and current status of anthelmintic resistance in Latvian sheep farms
}

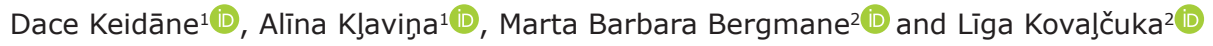 \\ 1. Institute of Food and Environmental Hygiene, Faculty of Veterinary Medicine, Latvia University of Life Sciences and \\ Technologies, K. Helmana street 8, Jelgava, LV-3004, Latvia; 2. Clinical Institute, Faculty of Veterinary Medicine, Latvia \\ University of Life Sciences and Technologies, K. Helmana street 8, Jelgava, LV-3004, Latvia. \\ Corresponding author: Līga Kovalčuka, e-mail: kovalcuka@gmail.com \\ Co-authors: DK: dacekeidane@gmail.com, AK: alina.visocka@llu.Iv, MBB: martabbergmane@gmail.com \\ Received: 12-09-2021, Accepted: 18-01-2022, Published online: 23-02-2022
}

doi: www.doi.org/10.14202/vetworld.2022.414-418 How to cite this article: Keidāne D, Klavina A, Bergmane MB, Kovalčuka L (2022) Parasitofauna and current status of anthelmintic resistance in Latvian sheep farms, Veterinary World, 15(2): 414-418.

\begin{abstract}
Background and Aim: Parasitic invasions, especially gastrointestinal nematodes, are widespread and are one of the main problems in sheep farms. For this reason, sheep are dewormed more often than other livestock species, often several times a year. Concerns about antiparasitic resistance from the farmers and veterinarians have arisen because, on some farms, antiparasitic drugs are used routinely for very long periods. There are no data available on anthelmintic resistance in gastrointestinal nematodes in sheep in Latvia. Our work aimed to determine the most common endoparasites in sheep and the degree of anthelmintic resistance on sheep farms in Latvia.
\end{abstract}

Materials and Methods: All sheep (577) underwent a coprological examination before the start of the study, and only sheep diagnosed with more than 200 McMaster eggs per gram of feces were included in the study. A fecal egg count reduction (FECR) test was performed on 20 sheep flocks in Latvia.

Results: In Latvia, sheep were most commonly infected with Eimeria spp. 97\% (confidence interval [CI] 95\% 96-98). The second most commonly diagnosed species were Trichostrongylidae 91\% (CI 95\% 89-93) and Strongyloides spp. $76 \%$ (CI 95\%, 72-79). The ivermectin (IVM) FECR was 0.74\% (0.73-0.74), showing resistance in all sheep farms included in this study. Albendazole (ABZ) FECR 0.89\% (0.88-0.89) was effective.

Conclusion: This study showed that the most popular deworming drugs (ivermectin, albendazole) in Latvia are ineffective in sheep. Additional studies on the use of IVM+ABZ combinations for deworming sheep should be performed.

Keywords: anthelmintic resistance, gastrointestinal parasites, sheep.

\section{Introduction}

Sheep are often infected with Trichostrongylidae (Haemonchus spp., Ostertagia spp., and Trichostrongylus spp.) [1,2]. Among the cestodes, the current invasion of sheep is monieziosis. Protozoa disease, eimerosis is more common in Latvia in lambs. Latvia is not an exception among European countries and they are also troubled by the same types of parasites. Due to climate change, sheep farms are increasingly facing problems caused by these parasites. The sheep are often clinically ill with diarrhea, reduced body weight, developmental delays, and death [1].

Parasitic invasions and their possible control are widespread concerns in veterinary medicine, especially on sheep farms. Studies in many countries have shown that anthelmintic resistance in sheep farming is a global problem. The first reports of anthelmintic resistance appeared in the early 1990s [3].

Copyright: Keidāne, et al. Open Access. This article is distributed under the terms of the Creative Commons Attribution 4.0 International License (http://creativecommons.org/licenses/ by/4.0/), which permits unrestricted use, distribution, and reproduction in any medium, provided you give appropriate credit to the original author(s) and the source, provide a link to the Creative Commons license, and indicate if changes were made. The Creative Commons Public Domain Dedication waiver (http:// creativecommons.org/publicdomain/zero/1.0/) applies to the data made available in this article, unless otherwise stated.
The current research has also been conducted in European countries such as Austria, Denmark, Italy, Spain, the Netherlands, the Czech Republic, Greece, and Lithuania [4-9]. Anthelmintic resistance seems to be quite common in practical veterinary medicine. However, unfortunately, there have been no studies conducted in Latvia thus far. It should be noted that there are few deworming products for sheep registered in Latvia; ivermectin (IVM), levamisole (LEV), albendazole (ABZ), closantel, and monepantel are available for deworming in sheep. IVM (macrocyclic lactone) and ABZ (benzimidazole) are more commonly used [10]. IVM is also used to control ectoparasites, but $\mathrm{ABZ}$ is used to control monieziosis.

No less relevant is the issue of methods for detecting antiparasitic resistance. The currently used method for antiparasitic detection is counting parasitic eggs before and after deworming - the fecal egg count reduction test (FECRT). This method is used by most scientists $[4,6,9,11,12]$. Recently, publications have appeared where FECRT is combined with molecular testing methods. Some authors also suggest combining molecular methods with FECRT $[8,13,14]$.

This study aimed to determine the most common endoparasites in sheep and the degree of anthelmintic resistance in sheep farms in Latvia. 


\section{Materials and Methods}

\section{Ethical approval and Informed consents}

Ethical approval was not required to conduct this study. In all cases, written informed consent was obtained from the farm owners for the study.

\section{Study period, location, and the sampling procedure}

This study was conducted in September and October 2019 and 2020. In this study, 20 sheep farms from all regions of Latvia were included (six in Vidzeme, eight in Kurzeme, three in Zemgale, and three in Latgale). The sheep farms were divided into small farms, where the number of sheep was less than or equal to 100 animals $(n=7)$, average with $100-300$ animals $(n=10)$, and large farms with more than 300 sheep $(n=3)$. On each farm, depending on the size of the farm, study groups of sheep were created (ewes that were 3 or more years old). On small farms, 10\% of the sheep from the total herd were included in this study, while it was up to $20 \%$ from medium and large farms. All animals underwent a coprological examination before the start of the study, and to obtain statistically relevant data, only sheep diagnosed with more than 200 McMaster eggs per gram of feces (EPGs) were included in the study [13].

To evaluate the effectiveness of deworming agents, a coprological sample was taken rectally from each sheep before deworming and 14 days after deworming. Coprological samples were taken while wearing polyethylene gloves, labeled, and placed in cold boxes. The samples were delivered to the laboratory within a day and examined within 2 days. In the laboratory, the coprological samples were stored in a refrigerator at $4^{\circ} \mathrm{C}$ until the time of analysis.

\section{Treatment groups and medications}

For sheep deworming, registered anthelmintic medications were used chosen by the farmer or the veterinarian. If the farm had been using a particular drug for several years, we used the same drug on the sheep on each particular farm.

In this study, 10 farms used IVM $1 \% 0.2 \mathrm{mg} / \mathrm{kg}$ (Biomectin 1\%, Vetoquinol Biowet, Poland), 10 farms used ABZ 10\% $5 \mathrm{mg} / \mathrm{kg}$ (Albex 10\%, Chanelle, UK), and three farms used an IVM 1\% $0.2 \mathrm{mg} / \mathrm{kg} / \mathrm{ABZ} 10 \%$ $5 \mathrm{mg} / \mathrm{kg}$ combination. Initially, the study included farms that used Ivomec Plus (IVM 1\% and clorsulon $10 \%$ ), closantel $50 \mathrm{mg} / \mathrm{ml}$, monepantel $25 \mathrm{mg} / \mathrm{ml}$, and LEV $11.8 \%$ for deworming sheep. Due to the insufficient number of animals in each group, these farms were not included in the analyses.

\section{Statistical analysis}

To determine the parasitofauna on the farms, we examined the coprological samples of sheep according to the methods ofMcMaster and Baermann [13]. For the diagnosed parasites, we determined the invasion prevalence in percentages and the invasion intensity (total egg count per sheep) in the averages. Coprological samples of sheep taken both before and on the $14^{\text {th }}$ day were examined by the McMaster method. We took $4 \mathrm{~g}$ of sheep feces mixed with $56 \mathrm{ml} \mathrm{NaCl}$ (density 1.20 [0.5 moL/L]). We examined the McMaster chamber and calculated the worm load according to the standard formula. Individual FECs, expressed in EPG, were calculated using the McMaster technique. The mean FECR for each group and the corresponding 95\% confidence intervals (CIs) were calculated as follows:

FECR $\%=100 \% \times\left(1-\mathrm{m}^{2} / \mathrm{m} 1\right)$,

whereas, $\mathrm{m} 1=$ arithmetic mean FEC across the animals excreting eggs before treatment and $\mathrm{m} 2=$ arithmetic mean FEC after treatment [5,15].

Three result labels were developed to interpret the results based on Coles et al. [12]. If the FECR $<95 \%$, then the farm is dominated by a population of resistant (R) Trichostrongylidae. In contrast, if the FECR is $\geq 95 \%$, then Trichostrongylidae is susceptible (S). Results that do not fall within these ranges are referred to as the suspended population $(\mathrm{R} / \mathrm{S})$.

\section{Results}

This study showed that sheep in Latvia are infested with parasites such as Eimeria spp., Trichostrongylidae, Strongyloides spp., Trichuris spp., Capillaria spp., Moniezia spp., and Protostrongylidae. The prevalence $\%$ of the diagnosed parasites is shown in Table-1.

Sheep weremost commonly infected with Eimeria spp. 97\% (CI 95\% 96-98). The second most commonly diagnosed infestations were Trichostrongylidae 91\% (CI 95\% 89-93) and Strongyloides spp. 76\% (CI 95\% 72-79). On some farms, Trichostrongylidae invasions recur yearly and cause significant economic losses to the animal owners. The third most common infestation in sheep farms was Moniezia spp. 77\%. Moniezia spp. invasion on sheep farms is often diagnosed, and although clinical signs are rare in adult sheep, they cause serious health problems in lambs, which are clinically manifested by diarrhea, weight loss, developmental delays, and even animal death. Less frequently, we diagnosed Trichuris spp. invasion $0.5 \%$, Capillaria spp. $0.2 \%$, and Protostrongylidae $0.2 \%$. The intensity of the invasion is shown in Table-1.

The highest intensity of invasion was in sheep invaded with Eimeria spp. in the average of $1478(95 \% \mathrm{CI} 190-2766)$. Eimeria was diagnosed on all study farms $(p=0.0792)$. The intensity of Trichostrongylidae invasion was an average of 1056 (95\%CI 821-1290), and this invasion, similar to Eimeria, was diagnosed on all sheep farms included in this study ( $\mathrm{p}=0.0674)$. The intensity of Trichuris invasion was an average of 63 (95\% CI 23-102), and this invasion was diagnosed on two farms. On one farm, Trichuris invasion was diagnosed in one sheep, and on another farm, three sheep were diagnosed. We diagnosed Moniezia invasion from cestodes with an average of 616 (95\%CI 199-1033). During the study, only five farms were not diagnosed with monieziosis in the coprological samples taken before or after deworming 
$(\mathrm{p}=1.2800)$. In one farm, in two animals, Capillaria with an average invasion intensity of 75 (95\% CI 0-393) were diagnosed (according to McMaster). Protostrongylidae was diagnosed in two sheep farms, incomplete four sheep, and the average invasion intensity was 2 (95\%CI 0-79). The most common invasions that cause economic losses in sheep farms in Latvia are nematodes of the family Trichostrongylidae. The effectiveness of the deworming agents on sheep farms is shown in Table- 2 .

For sheep deworming, we used $0.2 \mathrm{mg} / \mathrm{kg}$ IVM subcutaneously, $5 \mathrm{mg} / \mathrm{kg} \mathrm{ABZ}$ orally, and an $\mathrm{IVM}+\mathrm{ABZ}$ combination. Among the 10 sheep farms included in the study that used IVM, two farms did not show anthelmintic resistance when calculating FECR\%. However, when calculating CI, farm No. 5 showed $0.95 \%(0.89-0.99 \%)$ and farm No.7 $0.92 \%$ (0.85-0.95\%), which means that there may be resistance in a larger number of animals. As a result, the parasites may have developed resistance on all sheep farms where IVM was used. Ten farms that used ABZ for deworming sheep were tested for resistance; four farms were free of resistance, and resistance was questionable in two (farm No. 17 FECR\% 0.90 [0.88-0.91] and farm No.8 0.91 [0.87-0.94]). In three farms, where sheep were dewormed with IVM+ABZ combinations, one farm showed FECR resistance of 0.89\% (0.85-0.92\%), but farms No. 19 and No. 20 had no resistant parasites. Farm No. 8, which used IVM, $\mathrm{ABZ}$, and IVM+ABZ combinations, had resistance against all drugs included in this study. In addition, farm No. 6, IVM and ABZ were ineffective. It should

Table-1: Invasion prevalence \% and invasion intensity in sheep farms in Latvia.

\begin{tabular}{|c|c|c|c|c|}
\hline Invasion & $\begin{array}{l}\text { Prevalence\%, } \\
\quad(95 \% \mathrm{CI})\end{array}$ & $\begin{array}{c}\text { Invasion intensity } \\
(95 \% \mathrm{CI})\end{array}$ & $\begin{array}{c}\text { Positive sheep/total } \\
\text { number of sheep }\end{array}$ & $\begin{array}{l}\text { Eggs count } \\
(\min -\max )\end{array}$ \\
\hline Eimeria spp. & $\begin{array}{c}97 \% \\
(96-98)\end{array}$ & $\begin{array}{c}1478 \\
(190-2766)\end{array}$ & $290 / 577$ & $(50-178950)$ \\
\hline Trichostrongylidae & $\begin{array}{c}91 \% \\
(89-93)\end{array}$ & $\begin{array}{c}1056 \\
(821-1290)\end{array}$ & $331 / 577$ & $(50-23750)$ \\
\hline Strongyloides spp. & $\begin{array}{c}76 \% \\
(72-79)\end{array}$ & $\begin{array}{c}215 \\
(111-319)\end{array}$ & $59 / 577$ & $(50-2600)$ \\
\hline Trichuris spp. & $\begin{array}{c}0,5 \% \\
(0,1-1,5)\end{array}$ & $\begin{array}{c}63 \\
(23-102)\end{array}$ & $4 / 577$ & $(50-100)$ \\
\hline Capillaria spp. & $\begin{array}{c}0,2 \% \\
(0-1)\end{array}$ & $\begin{array}{c}75 \\
(0-393)\end{array}$ & $2 / 577$ & $(50-100)$ \\
\hline Moniezia spp. & $\begin{array}{c}77 \% \\
(73-80)\end{array}$ & $\begin{array}{c}616 \\
(199-1033)\end{array}$ & $44 / 577$ & $(50-7550)$ \\
\hline Protostrongylidae & $\begin{array}{c}0,2 \% \\
(0-1)\end{array}$ & $\begin{array}{c}2 \\
(0-79)\end{array}$ & $2 / 577$ & $(1-2)$ \\
\hline
\end{tabular}

Table-2: Anthelmintic efficacy of sheep farms.

\begin{tabular}{|c|c|c|c|c|}
\hline $\begin{array}{l}\text { Sheep } \\
\text { farms }\end{array}$ & $\begin{array}{l}\text { Anthelmintic class/ } \\
\text { No. of animals included }\end{array}$ & $\begin{array}{c}\text { Mean EPG value before/ } \\
\text { after treatment }\end{array}$ & $\begin{array}{l}\text { FECR\% } \\
(95 \% \mathrm{CI})\end{array}$ & Status \\
\hline 1 & IVM/18 & $786 / 106$ & $0.87(0.81-0.90)$ & $\mathrm{R}$ \\
\hline 2 & IVM/9 & $361 / 78$ & $0.78(0.63-0.88)$ & $\mathrm{R}$ \\
\hline 3 & IVM/20 & $1020 / 187$ & $0.81(0.77-0.86)$ & $\mathrm{R}$ \\
\hline 4 & IVM/44 & $1577 / 515$ & $0.68(0.64-0.71)$ & $\mathrm{R}$ \\
\hline 5 & IVM/15 & $290 / 13$ & $0.95(0.89-0.99)$ & SR \\
\hline 6 & IVM/8 & $1888 / 806$ & $0.56(0.54-0.60)$ & $\mathrm{R}$ \\
\hline \# & $A B Z / 20$ & $1887 / 312$ & $0.83(0.82-0.84)$ & $\mathrm{R}$ \\
\hline 7 & IVM/15 & $477 / 40$ & $0.92(0.85-0.95)$ & SR \\
\hline 8 & IVM/18 & $644 / 279$ & $0.56(0.53-0.60)$ & $\mathrm{R}$ \\
\hline \# & $A B Z / 15$ & $1140 / 103$ & $0.91(0.87-0.94)$ & SR \\
\hline \# & $\mathrm{IVM}+\mathrm{ABZ} / 20$ & $903 / 100$ & $0.89(0.85-0.92)$ & $\mathrm{R}$ \\
\hline 9 & IVM/20 & $3370 / 905$ & $0.73(0.68-0.77)$ & $\mathrm{R}$ \\
\hline 10 & IVM/18 & $3231 / 678$ & $0.79(0.76-0.82)$ & $\mathrm{R}$ \\
\hline 11 & $A B Z / 20$ & $460 / 130$ & $0.72(0.62-0.80)$ & $\mathrm{R}$ \\
\hline 12 & $A B Z / 18$ & $672 / 39$ & $0.94(0.90-0.97)$ & $S$ \\
\hline 13 & $\mathrm{ABZ} / 16$ & $938 / 119$ & $0.87(0.86-0.89)$ & $\mathrm{R}$ \\
\hline 14 & $\mathrm{ABZ} / 20$ & $945 / 10$ & $0.99(0.98-100)$ & $\mathrm{S}$ \\
\hline 15 & $\mathrm{ABZ} / 15$ & $530 / 0$ & $100(0.98-100)$ & $\mathrm{S}$ \\
\hline 16 & $\mathrm{ABZ} / 20$ & $1562 / 247$ & $0.84(0.81-0.87)$ & $\mathrm{R}$ \\
\hline 17 & $\mathrm{ABZ} / 20$ & $767 / 80$ & $0.90(0.88-0.91)$ & SR \\
\hline 18 & $A B Z / 20$ & $613 / 3$ & $100(0.98-100)$ & $\mathrm{S}$ \\
\hline 19 & IVM+ABZ/20 & $825 / 32$ & $0.96(0.93-0.98)$ & $\mathrm{S}$ \\
\hline 20 & $\mathrm{IVM}+\mathrm{ABZ} / 20$ & $637 / 0$ & $100(100-100)$ & $\mathrm{S}$ \\
\hline
\end{tabular}

IVM-Ivermectin; ABZ - Albendazol; IVM + ABZ combination; Mean eggs per gram of faeces (EPG); faecal eggs count reduction percentages (FECR\%) and 95\% confidence intervals (CI); status R - resistance, S -susceptible, $\mathrm{SR}$ - suspected of resistance 
be noted that farms with resistance to the above drugs had been using them consistently for 5 years or more. It is also important to note that deworming was carried out several times a year on farms with resistance. On farms, where no resistance was found, deworming was performed only once or twice a year (in spring and autumn), and sheep breeding was carried out for a relatively short time.

\section{Discussion}

This study aimed to determine the most common endoparasites in sheep and the degree of anthelmintic resistance in sheep farms in Latvia. The data obtained in this study on the most common sheep parasitosis are to some extent similar to those from other countries [2,6,16-18]. In Latvia, Eimeria spp. 97\% and Trichostrongylidae invasion are quite common in sheep, Strongyloides spp. is less often diagnosed at $76 \%$ and Moniezia spp. at $77 \%$ are diagnosed less frequently. In Sweden, the invasion intensity of some sheep flocks in Haemonchus was 90-100\%; however, Eimeria was diagnosed in all sheep flocks studied [19], Rinaldi et al. [20] noted that in Austria, the extent of Haemonchus invasion in sheep farms was $77 \%$; in Italy, it was $73 \%$; and in Ireland, it was only $4 \%$. In Spain, studies on sheep have shown an intensity of invasion of up to $100 \%$ for nematodes of the family Trichostrongylidae [2]. So far, there are no data on which species of Trichostrongylidae (Haemonchus, Ostertagia, or Trichostrongylus) predominate in sheep farms in Latvia. Obviously, as the climate changes animal movement between countries increases, these invasions will have to be increasingly considered in the future. The lack of availability of effective anthelmintics is a cause for concern.

This study on antiparasitic resistance in sheep was conducted for the $1^{\text {st }}$ time in Latvia. We found that the most commonly used drugs in Latvia for the control of Trichostrongylidae are IVM and ABZ. Less commonly used are monepantel, LEV, and closantel. In our study, these drugs were used on only three sheep farms. Trichostrongylidae invasions are resistant to IVM and ABZ worldwide, including in Latvia, potential alternative medicines options and prevention measures in sheep farms is becoming prominent. Research on antiparasitic resistance is emerging worldwide [9,21-26]. Major sheep farms in Europe have noted anthelmintic resistance. As mentioned, resistance to ABZ in sheep is particularly notable in many European countries [1,9,21,23,25,26], where resistance to $\mathrm{ABZ}$ has also been reported. In addition to ABZ resistance, there are studies of LEV and IVM resistance in the UK $[1,27,28]$. Our study found antiparasitic resistance on essentially all 10 farms that regularly used IVM. Sheep farms using ABZ performed better. This is probably because IVM is used more often in Latvia for deworming sheep than ABZ, historically, and as the price difference between the two drugs is also significant. The FECR was above
$90 \%$ in five farms, while the FECR was below $90 \%$ in five other farms. Among the three farms included in this study that used the IVM+ABZ combination as an anthelmintic, we found FECRs lower than $90 \%$ in one farm. In Lithuania, IVM resistance was detected in two of 16 sheep farms, and FBZ resistance was detected in three farms [29]. The situation is similar in similar studies in Belgium [4], the Netherlands [5], Denmark [6], Austria [30], France, Greece, and Italy [31].

In parallel with this study, another study was performed to investigate parasite prevention measures in sheep farms. Preliminary data from this study show that the most common errors during deworming sheep are excessive use, repeatedly using antihelmintic drugs at the inappropriate dose, administration route, ignoring official storage, and use rules [32].

\section{Conclusion}

This study showed that the most popular deworming drugs in Latvia are ineffective in sheep. The IVM FECR was $0.74 \%(0.73-0.74)$, showing resistance in all sheep farms included in this study. ABZ FECR $0.89 \%(0.88-0.89)$ was effective. Additional studies on the use of IVM $+\mathrm{ABZ}$ combinations for deworming sheep should be performed. The limitation of the study, is that we used a small number of farms. The authors suggest a future study with a more number of farms involvement for the in-depth information.

\section{Authors' Contributions}

DK and LK: Conceptualization, methodology, and writing of the original draft. LK, DK, AK, and MBB: Sample collection, laboratory work, data curation, equally conceived the work with literature, and drafted and reviewed the manuscript. LK, DK, and AK: Drafted and revised the manuscript. All authors have read and approved the final manuscript.

\section{Acknowledgments}

This study was funded by the framework of Latvia University of Life Sciences and Technologies (LLU), specifically: "Antiparasitic drug resistance in Latvian sheep farms" (Grant number LLU P12).

\section{Competing Interests}

The authors declare that they have no competing interests.

\section{Publisher's Note}

Veterinary World remains neutral with regard to jurisdictional claims in published institutional affiliation.

\section{References}

1. Taylor, M.A., Learmount, J., Lunn, E., Morgan, C. and Crang, B.H. (2009) Multiple resistance to anthelmintics in sheep nematodes and comparison of methods used for their detection. Small Rumin. Res., 86(1-3): 67-70.

2. Pedreira, J., Paz-Silva, S., Sanchez-Andrade, R., Suarez, J.L., Arias, M., Lomba, C., Diaz, P., Lopez, C., 
Diez-Banos, P. and Morrondo, P. (2006) Prevalences of gastrointestinal parasites in sheep and parasite-control practices in NW Spain. Vet. Med., 75(1-2): 56-62.

3. Kaplan, R.M. and Vidyashankar, A.N. (2012) An inconvenient truth: Global worming and anthelmintic resistance. Vet. Parasitol., 186(1-2): 70-78.

4. Claerebout, E., De Wildea, N., Van Mael, E., Casaert, S., Vande Velde, F., Roeber, F., Veloz, V.P., Levecke, B. and Geldhof, P. (2020) Anthelmintic resistance and common worm control practices in sheep farms in Flanders, Belgium. Vet. Parasitol. Reg. Stud. Rep., 20: 100393.

5. Ploeger, H.W. and Everts, B.B. (2018) Alarming levels of anthelmintic resistance against gastrointestinal nematodes in sheep in the Netherlands. Vet. Parasitol., 262: 11-15.

6. Pena-Espinoza, M., Thamsborg, S.M., Demeler, J. and Enemarka, H.L. (2014) Field efficacy of four anthelmintics and confirmation of drug-resistant nematodes by controlled efficacy test and pyrosequencing on a sheep and goat farm in Denmark. Vet. Parasitol., 206(3-4): 208-215.

7. Kupčinskas, T., Stadaliene, I., Šarkunas, M., Riškevičiene, V., Varady, M., Hoglund, J. and Petkevičius, S. (2015) Prevalence of anthelmintic resistance on Lithuanian sheep farms assessed by in vitro methods. Acta Vet. Scand., 57(1): 88.

8. Roeber, F., Jex, A.R. and Gasser, B.G. (2013) Impact of gastrointestinal parasitic nematodes of sheep, and the role of advanced molecular tools for exploring epidemiology and drug resistance. Aust. Perspect. Parasit. Vectors, 6(1): 153.

9. Papadopoulos, E., Gallidis, E. and Ptochos, S. (2012) Anthelmintic resistance in sheep in Europe: A selected review. Vet. Parasitol., 189(1): 85-88.

10. Kḷaviņa, A., Keidāne, D., Grasberga M.B. and Kovaḷčuka, L. (2021) Most Common Antiparasitic Drug Usage Mistakes in Sheep Farms in Latvia. Scandinavian-Baltic Society for Parasitology, abstract Book, Vilnius, Lithuania, April 21-23, 2021/Nature Research Centre, Young Academy of Lithuanian Academy of Sciences, Scandinavian-Baltic Society for Parasitology. p98. Available from: https://backend.orbit.dtu.dk/ws/portalfiles/portal/245625751/Abstract_ Book_final_CSBSP9.pdf Retrieved on 09-02-2022.

11. Palcy, C., Silvestre, A., Sauve, C., Cortet, J. and Cabaret, J. (2010) Benzimidazole resistance in Trichostrongylus axei in sheep: Long-term monitoring of affected sheep and genotypic evaluation of the parasite. Vet. J., 183(1): 68-74.

12. Coles, G.C., Jackson, F., Pomroy, W.E., Prichard, R.K., Von Samson Himmelstjerna, G., Silvestre, A., Taylor, M.A. and Vercruysse, J. (2006) The detection of anthelmintic resistance in nematodes of veterinary importance. Vet. Parasitol., 136(3-4): 167-185.

13. Gainza, Y.A., dos Santos, I.B., Figueiredo, A., Lima dos Santos, L.A., Esteves, S.N., Barioni-Junio, W., Minho, A.P. and Chagas, A.C.S. (2021) Anthelmintic resistance of Haemonchus contortus from sheep flocks in Brazil: Concordance of in vivo and in vitro (RESISTA-TestC) methods. Rev. Bras Parasitol. Vet., 30(2): e025120.

14. Barrere, V., Falzon, L.C. Shakya, K.P., Menzies, P.I., Peregrine, A.S. and Prichard, R.K. (2013) Assessment of benzimidazole resistance in Haemonchus contortus in sheep flocks in Ontario, Canada: Comparison of detection methods for drug resistance. Vet. Parasitol., 198(1-2): 159-165.

15. Wang, C., Torgerson, P.R., Kaplan, R.M., George, M.M. and Furrer, R. (2018) Modelling anthelmintic resistance by extending egg counts package to allow individual efficacy. Int. J. Parasitol. Drugs Drug Resist., 8(3): 386-393.

16. Vlassoff, A. and McKenna, P.B. (1994) Nematode parasites of economic importance in sheep in New Zealand. N. Z. J. Zool., 21(1): 1-8.

17. Torgerson, P.R., Paul, M. and Furrer, R. (2014) Evaluating faecal egg count reduction using a specifically designed package egg counts in $\{\mathrm{R}\}$ and a user-friendly web interface. Vet. Parasitol., 44(5): 299-303.

18. Chaparro, J.J., Villar, D., Zapata, J.D., López, S., Howell, S.B., López, A. and Storey, B.E. (2017) Multidrug resistant Haemonchus contortus in a sheep flock in Antioquia, Colombia. Vet. Parasitol. Reg. Stud., 10: 29-34.

19. Waller, P.J. and Thamsborg, S.M. (2004) Nematode control in green ruminant production systems. Trends Parasitol., 20(10): 493-497.

20. Rinaldi, L., Catelan, D., Musella, V. and Cesoni, L. (2015) Haemonchus contortus: Spatial risk distribution for infection in sheep in Europe. Geospat. Health, 9(2): 325-331.

21. Chartier, C., Pors, I., Hubert, J., Rocheteau, D., Benoit, C. and Bernard, N. (1998) Prevalence of anthelmintic resistant nematodes in sheep and goats in western France. Small Rumin. Res., 29(1): 33-41.

22. Traversa, D., Paoletti, B., Otranto, D. and Miller, J. (2007) First report of multiple drug resistance in Trichostrongyles affecting sheep under field conditions in Italy. Parasitol. Res., 101(6): 1713-1716.

23. Domke, A.V.M., Chartier, C., Gjerde, B., Hoglund, J., Lene, N., Vatn, S. and Stuen, S. (2012) Prevalence of anthelmintic resistance in gastrointestinal nematodes of sheep and goats in Norway. Parasitol. Res., 111(1): 185-193.

24. Good, B., Hanrahan, J.P., de Waal, D.T., Patten, T., Kinsella, A. and Lynch, C.O. (2012) Anthelmintic-resistant nematodes in Irish commercial sheep flocks the state of play. Ir. Vet. J., 65(1): 21.

25. Martinez-Valladares, M., Martinez-Perez, J.M., RoblesPerez, D., Cordero-Perez, C., Famillaro, M.R., FernandezPato, N., Castanon-Ordonez, L. and Rojo-Vazouez, F.A. (2013) The present status of anthelmintic resistance in gastrointestinal nematode infections of sheep in the Northwest of Spain by in vivo and in vitro techniques. Vet. Parasitol., 191(1-2): 177-181.

26. McMahon, C., McCoy, M., Ellison, S.E., Barley, J.P., Edgar, H.W.J., Hanna, R.E.B., Malone, F.E., Brennan, G.P. and Fairweather, I. (2013) Anthelmintic resistance in Northern Ireland (III): Uptake of "SCOPS" (sustainable control of parasites in sheep) recommendations by sheep farmers. Vet. Parasitol., 193(1-3): 179-184.

27. Sargison, N., Scott, P., Wilson, D., Macrae, A. and Penny, C. (2010) Teladorsagia circumcincta resistance to moxidectin and multiple anthelmintic groups in ewes following use of the persistent drug before lambing. Vet. Rec., 167(14): 523-527.

28. Mitchell, E.S., Hunt, K.R., Wood, R. and McLean, B. (2010) Anthelmintic resistance on sheep farms in Wales. Vet. Rec., 166(21): 650-652.

29. Kupčinskas, T., Stadaliene, L., Šalomskas, A., Trusevičius, P., Varady, M. and Petkevičius, S. (2016) Worm-control practices and prevalence of anthelmintic resistance using in vivo FECRTs on smallholder sheep farms in Lithuania. Helminthol, 53(1): 24-30.

30. Untersweg, F., Fernerl, V., Wiedermann, S., Göller, M., Hörl-Rannegger, M., Kaiser, W., Joachim, A., Rinaldi, L., Krücken, J. and Hinney, B. (2021) Multispecific resistance of sheep trichostrongylids in Austria. Parasite, 28(Jun): 50.

31. Geurden, T., Hoste, H., Jacquiet, P., Traversa, D., Sotiraki, D., Frangipane di Regalbono, A., Tzanidakis, N.,Kostopoulou, D., Gaillac, C.,Privat, S., Giangaspero, A., Zanardello, C., Noé, L., Vanimisetti, B. and Bartram, D. (2014) Anthelmintic resistance and multidrug resistance in sheep gastro-intestinal nematodes in France, Greece and Italy. Vet. Parasitol., 201(1-2): 59-66.

32. Kovalcuka, L., Keidane, D., Klavina, A., Grasberga, M.B. and Veksins, A. (2022) Most common inappropriate drug usage factors in anthelmintic treatment on sheep farms in Latvia. Vet. World., 15(2): 244-251. 